\title{
Jornalismo e credibilidade: Uma percepção do público
} Journalism and credibility: A perception of the public

\author{
Dra. Angela Maria Grossi \\ Universidade Estadual Paulista (UNESP) \\ angela.grossi@unesp.br \\ ORCID: https://orcid.org/0000-0002-5425-4917 \\ Gabriella Soares dos Santos \\ Universidade Estadual Paulista (UNESP) \\ gabriella.soaresds@gmail.com \\ ORCID: https://orcid.org/0000-0002-5481-7265
}

Resumo: A credibilidade é um dos fatores que permitem que o jornalismo exerça uma função social dentro de uma democracia, no entanto nos últimos anos a ideia de uma crise jornalística generalizada tem ganhado força entre profissionais e público. Com base nesse cenário, buscamos realizar uma pesquisa qualitativa que apontasse de qual forma o leitor se relaciona com as notícias e com os meios de comunicação aos quais têm acesso no que diz respeito à credibilidade e à confiança, elementos essenciais para garantir uma real função social à essa prática profissional. Dessa forma, traçamos quais são os critérios objetivos mais importantes para o público na atribuição da credibilidade e buscamos comparar os resultados com os critérios de qualidade indicados pelos profissionais de jornalismo como indicação de um trabalho credível. Como resultado, é possível observar que, apesar dos padrões estarem alinhados, há uma disparidade entre aquilo que seria ideal para os dois pólos comunicacionais e aquilo que o público percebe nos produtos aos quais tem acesso em seu dia a dia e com base no que, consequentemente, atribui credibilidade aos materiais jornalísticos. Essa distância pode ser parcialmente explicada com base na ideia de que a confiança e a credibilidade são elementos que contam, em sua atribuição, com muitos critérios subjetivos, mas também levanta a questão da qualidade da conexão e do diálogo entre os polos comunicacionais que constituem o jornalismo. 
Abstract: Credibility is one of the factors that allow journalism to play a social role within a democracy, however in recent years the idea of a generalized journalistic crisis has gained strength among professionals and the public. Based on this scenario, we seek to carry out a qualitative research that points out how the reader relates to the news and the media to which they have access with regard to credibility and trust, essential elements to guarantee a real social role to this professional practice. That way, we outline the most important objective criteria for the public in the attribution of credibility and seek to compare the results with the quality criteria indicated by journalism professionals as an indication of credible work. As a result, it is possible to observe that, although the patterns are aligned, there is a disparity between what would be ideal for the two communicational poles and what the public perceives in the products to which they have access and based on what, consequently, it attributes credibility to journalistic materials. This distance can be partially explained on the basis of the idea that trust and credibility are elements that count with many subjective criteria, but also raises the question of the quality of the connection and the dialogue between the communicational poles that constitute journalism.

Palavras-chave: Jornalismo, Credibilidade, Confiança, Público

Key-words: Journalism, Credibility, Trust, Public

\section{INTRODUÇÃO}

Um dos fatores que permite que o Jornalismo tenha função social dentro de uma democracia é a confiança que o público escolhe depositar em seus produtos comunicacionais. Essa confiança, apesar de estar exposta a subjetividade dos indivíduos, também segue parâmetros objetivos e de importância técnica e teórica do Jornalismo: os critérios de credibilidade.

Essa relação entre confiança e credibilidade pode, muitas vezes, confundir conceitos e levar ao entendimento de que são basicamente a mesma coisa. No entanto, há diferenças epistemológicas significativas. A confiança pode ser entendida como um estado psicológico em que um indivíduo escolhe acreditar em algo ou alguém tendo a consciência de que isso é um ato vulnerável, já que não há formas de garantia (Rousseau,1998 apud Lewicki \& Tomlinson, 2003).

Os indicadores objetivos de que um meio de comunicação ou uma informação é credível foram mapeados pelo Trust Project ${ }^{1}$, ou Projeto Credibilidade, em seu capítulo brasileiro. Essa é uma iniciativa acadêmica e profissional que busca entender quais são os elementos que levam público e jornalistas a considerarem um conteúdo credível e confiável. Dentre as recomendações estão formas de ser mais transparente com o público, como por exemplo, ter um canal de feedback ou ainda especificar os códigos éticos que são seguidos pela organização ou simplesmente deixar claro quem foi o autor de tal informação ou reportagem jornalística. 
Figura 1 - Indicadores de credibilidade jornalística mapeados pelo Projeto Credibilidade.

\section{Melhores práticas}

Quem financia o veículo? Proprietários, sócios, patrocinadores?

Qual a missão do veículo?

Qual a data de fundação?

E os compromissos éticos: diversidade na equipe de reportagem/edição e de

vozes, precisão e política para correções, entre outros padrões

\section{Expertise do autor}

Detalhes sobre o jornalista que escreveu a matéria, incluindo expertise e outras

matérias em que atuou

\section{Tipo de etiquetagem}

Etiquetas para distinguir opinião, análise, humor e publicidade (conteúdo patrocinado) de reportagens noticiosas

\section{Citações e referências}

Para matérias investigativas ou em profundidade, maior acesso às fontes por trás dos fatos e afirmações

Ver também: Métodos

\section{Métodos}

Informações sobre como os repórteres decidiram apurar a matéria e o que

fizeram durante o processo

Ver também: Citações e referências

\section{Apuração local?}

Permitir que as pessoas saibam quando a matéria tem origem ou expertise local

\section{Diversidade de vozes}

Os esforços da redação para trazer perspectivas diversas para a reportagem

\section{Feedback acionável}

estimular a colaboração do público, estabelecendo prioridades para a cobertura, contribuindo para o processo de reportagem e garantindo a precisão

Fonte: Projeto Credibilidade, 2018. 
Assim, não há nenhuma novidade no que é esperado do jornalismo para que Ihe seja atribuído credibilidade, pelo menos no que diz respeito ao público especializado (acadêmicos e profissionais de comunicação). Como explica Lisboa (2012, p. 13), "[...] as exigências que fazemos ao jornalismo e o modo como julgamos sua credibilidade são em grande medida as exigências e maneira pela qual atribuímos confiabilidade a qualquer tipo de fonte de informação com que travamos contato".

Assim, o problema da atribuição da credibilidade atualmente talvez esteja em seus aspectos subjetivos e em seu interlocutor. A importância de que jornalistas e outros profissionais envolvidos na cadeia produtiva das informações estejam cientes e cumpram com os requisitos colocados (Imagem 1) pelo Trust Project é clara. No entanto, se a maior parte do público não considerar ou ainda não perceber tais elementos a eficácia de uma notícia confiável e credível é duvidosa. Como afirmam Nurse, Agrafiotis, Creese, Goldsmith e Lamberts (2014, p. 02), esse é o ponto de complexidade, já que "[...] trust, credibility and quality (and the sub-factors of which they are comprised) are intrinsically subjective, i.e., they can be perceived and interpreted in different ways, and arguably may have varying levels of importance depending on the user of the information or the context"2.

E o ponto central desse desencontro do que profissionais e público esperam e avaliam em um conteúdo jornalístico vai de encontro com as expectativas e o papel atribuídos ao jornalismo atualmente. Uma possível leitura do que o público contemporâneo espera, como sugerem Carvalho e Belda (2017), é que a demanda se encontra em um jornalismo cidadão, dialógico, investigativo, transparente e autônomo política e economicamente. Novamente, não há novidades no que é exigido, apenas um público mais atento e crítico em relação à tais aspectos.

As transformações no ecossistema de mídias a partir da popularização das redes interconectadas redefiniram o campo do jornalismo, deslocando o seu lugar social: antigas práticas e métodos são insuficientes para as demandas contemporâneas, ao mesmo tempo em que o fluxo de boatos que varre as mídias sociais encontra na tradição jornalística da apuração e responsabilidade pela informação divulgada um capital simbólico a ser atualizado (Carvalho \& Belda, 2017, p. 02)

Tais expectativas ainda convivem, no entanto, com elementos ainda mais subjetivos para a decisão de se considerar ou não algo credível. A aderência do leitor com o discurso apresentado por uma matéria jornalística pode ser indispensável para essa determinação, inclusive ganhando em importância de aspectos objetivos como o grau de precisão da informação e a completude dos pontos de vista com que o tema foi retratado (Serra, 2006a).

A dinâmica dessa relação intersubjetiva é influenciada por diversos aspectos que podem estar ou não envolvidos na cadeia de produção noticiosa, como o clima político, econômico e social em uma determinada época e sociedade e a impressão, verídica ou não, de que a mídia está interferindo de alguma maneira nessa realidade. Dessa forma, pode ocorrer a desconfiança generalizada no conteúdo jornalístico atual e em seus atores.

A acurácia de um discurso está, portanto, sob domínio da fonte de informação, que precisa deixar claras suas intenções e dar garantias da veracidade do que está sendo dito. A forma do discurso e a transparência das intenções terão um impacto preponderante na percepção da credibilidade por parte do interlocutor. (Lisboa, 2012, p. 14). 
A incerteza do público nas intenções por trás de um conteúdo noticioso leva à desconfiança do mesmo. $\mathrm{E}$ esse sentimento, muitas vezes, independe da necessidade de se verificar a veracidade dos fatos ou os elementos internos de coesão de uma produção. Esse cenário leva, então, para uma perda de credibilidade de determinados autores, empresas ou até mesmo do jornalismo em si segundo a percepção do público.

\section{CRISE NA CREDIBILIDADE JORNALÍSTICA}

Com a disseminação da internet e os avanços tecnológicos na área de comunicação, as pessoas passaram a utilizar redes sociais como uma forma de publicar seus próprios conteúdos, incluindo os informativos. É nesse ambiente que diferentes formas de jornalismo prosperaram, sejam esses produzidos por jornalistas profissionais ou por cidadãos interessados e engajados em diferentes causas e assuntos.

A quantidade de conteúdo, consequentemente, também aumentou consideravelmente. $E$, enquanto a ideia de que mais pessoas têm o acesso e a possibilidade de publicar informações é um avanço, segundo a visão de que esse é quase um direito humano, também cria complexidades nas relações comunicacionais. A forma como a sociedade global se organiza política, social e economicamente faz com que a informação, online ou offline, torne-se muito importante (Nurse et al., 2014).

A popularização do termo fake news (notícias falsas) no último ano evidencia as incertezas que fazem parte das relações comunicacionais atuais. No entanto, a ideia de que é difícil saber se uma notícia é verídica ou se não foi facilmente assimilada por diferentes grupos, inclusive aqueles com propósitos particulares. Um exemplo disso, é a prática constante do presidente dos Estados Unidos, Donald Trump, de chamar toda matéria jornalística que não lhe agrada de "fake news". Assim, a distinção entre o que é credível e o que não é passa a ter grande importância mundial.

In this age characterized by a surplus of information from a variety of sources accessible to anyone online, credibility has become more important. Users sorting through a plethora of available information need to discern what to believe and what to dismiss as merely online chatter. This is especially true for younger people who rely on the Internet more than did older generations. (Swasy, Tandoc, Bhandari \& Davis, 2015, p. 226)3.

O resultado disso pode ser visto nos dados da pesquisa Edelman Trust Barometer, produzido pela Edelman Intelligence e pelo United Entertainment Group, divulgado sempre em janeiro do ano referente. Internacionalmente, esse é um dos principais indicadores do nível de confiança do público em relação aos meios de comunicação. Dados da edição de 2018 mostram que a confiança do público na instituição mídia apresentou melhora em relação aos últimos dois anos. Mas, ainda assim, o sentimento geral é de desconfiança.

A pesquisa impõe uma metodologia para a classificação de cada grupo. O "público informado" representa apenas $15 \%$ da população global, tem idade entre 25 e 64 anos, tem educação universitária, está no top $25 \%$ de renda de seu país e consome mídia e notícias de forma significativa. Por outro lado, a população geral se refere a todas as pessoas maiores de 18 anos, sem nenhum outro requisito.

Em uma comparação temporal, o Edelman Trust Barometer de 2016 mostrou que a mídia ainda se 
estabelecia como uma instituição confiável para $49 \%$ da população geral e para $56 \%$ da população informada. Ambas porcentagens registraram um crescimento em relação ao ano anterior, entretanto, o índice da população geral colocava a mídia como uma instituição próxima ao nível de não-confiabilidade.

Mas foi no final de 2016 que o contexto mundial contribuiu ainda mais para a percepção do jornalismo e de seu papel na sociedade ser alterado. A eleição estadunidense para presidente da república contou com uma campanha eleitoral massivamente focada no controle e na manipulação das informações, tanto pela candidata democrata Hillary Clinton quanto, e muitos dizem ainda mais, pelo republicano e presidente eleito Donald Trump.

Foi nesse momento histórico que a popularização do termo pós verdade se deu, ao ponto de ser considerada a palavra do ano pelo Dicionário Oxfor 4 . O substantivo composto pode ser entendido como a propensão de indivíduos se utilizarem de conteúdos que não correspondem à realidade factual para se informar, entender e agir em relação ao mundo. E falar de verdade, epistemologicamente, é algo complexo, o que dificultou e muito a discussão, ainda mais em um ambiente em que diversos interesses políticos, sociais e econômicos estavam envolvidos.

No entanto, como aponta Orlando Tambosi (2007), a verdade no jornalismo indica a correspondência dos fatos com a realidade. E essa realidade, embora muitos possam dizer que também é subjetiva, é vista por Aristóteles (apud Beneti \& Lisboa, 2015) como um contexto que é socialmente dividida e vista como comum por cada indivíduo. A verdade, nesse sentido, não é absoluta, pois é uma construção baseada na complexa realidade, ou seja, há verdades aproximadas, meias verdades, informações verdadeiras exageradas, manipuladas etc. (Tombosi, 2007).

Assim, a questão da pós-verdade não trata das diferentes interpretações que um mesmo fato pode ter na mídia, e sim das distorções de realidades factuais para atingir certo objetivo comunicacional. $\mathrm{E}$ como pode ser verificado no resultado do Edelman Trust Barometer de 2017, divulgado em janeiro do mesmo ano, esse complexo contexto influenciou na confiabilidade da mídia como uma instituição.

Segundo $57 \%$ da população global, a mídia não pode ser considerada confiável, foi o índice mais baixo registrado até aquele momento. Dos 28 países em que a pesquisa é realizada, apenas cinco consideravam as informações a que tinham acesso confiáveis. Segundo os autores da pesquisa esse cenário leva ao fenômeno conhecido pela metáfora "câmara de eco"5. A ideia, como explica Del Vicario (2016), é de que o ambiente das mídias sociais tem a tendência de ampliar e reforçar determinados conteúdos. Segundo o pesquisador, quando um grupo acredita em algo, cerca-se, nas mídias sociais, de pessoas que pensam o mesmo e compartilham entre si apenas informações que reafirmam as mesmas ideias e crenças. Assim, é criado um sistema em que opiniões ou fatos que de alguma forma refutem essas crenças nunca chegam aos indivíduos ou quando ocorre esse contato, esse grupo não está disposto a levar em consideração e muito menos mudar uma opinião.

Whether a news item, either substantiated or not, is accepted as true by a user may be strongly affected by social norms or by how much it coheres with the user's system of beliefs (58; 70). Despite enthusiastic claims that social media is generating a vast "collective intelligence" available to all (71), many mechanisms cause false information 
to gain acceptance, which in turn generate false beliefs that, once adopted by an individual, are highly resistant to correction $(72 ; 73 ; 74 ; 75)$. Using extensive quantitative analysis we show that social homogeneity is the primary driver of content diffusion, and one frequent result is the formation of homogeneous, polarized clusters (often called "echo chambers") (Del Vicario, 2016, p. 39)6.

É dessa forma que os resultados da pesquisa de 2017 podem ser compreendidos, por exemplo: $59 \%$ dos entrevistados dizem confiar em resultados informativos apresentados por «mecanismos de busca» e apenas $41 \%$ dizem o mesmo em relação a «editores humanos»; 53\% diz não ouvir com regularidade pessoas ou organizações com as quais não concordem; $52 \%$ admitem nunca ou raramente mudar de opinião em relação a temas sociais relevantes (Edelman Trust Barometer, 2017).

Nesse cenário, o ano de 2018 chega com poucas perspectivas de melhora em relação a percepção mundial da mídia. E, de fato, o Edelman Trust Barometer divulgado em janeiro de 2018 aponta que esta é a instituição que goza de menos confiança entre a população mundial, apenas $43 \%$ do público, como pode ser visto abaixo, na figura 2.

Figura 2 - Mídia é agora a instituição menos confiável.

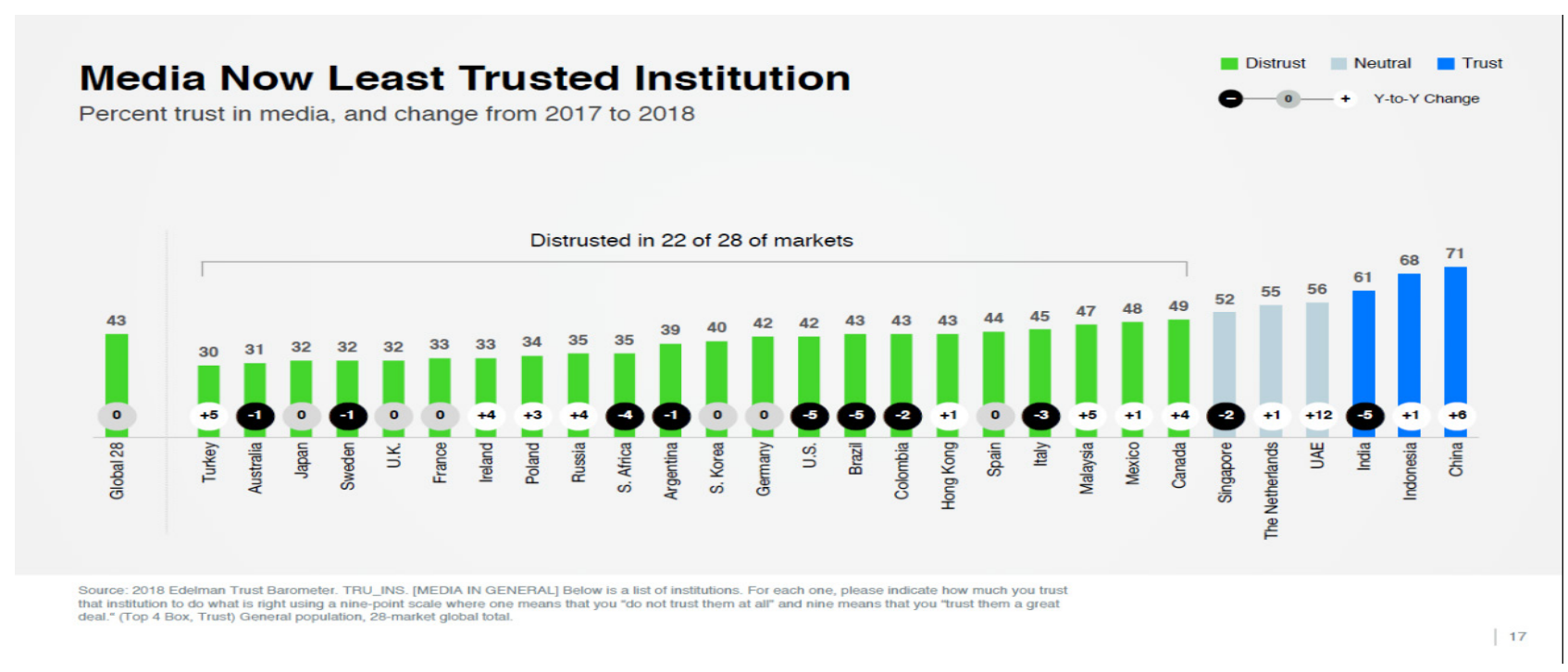

Fonte: Edelman Trust Barometer, 2018.

Os motivos para a desconfiança não se alterou durante esse espaço de tempo. A presença constante das notícias falsas em todo o mundo e a utilização do termo por políticos para, muitas vezes, distorcer a realidade e realizar uma guerra ideológica continua afetando a percepção do público. Segundo a pesquisa, a preocupação de que notícias falsas sejam utilizadas como uma arma está presente em diversos países, inclusive em mais de $70 \%$ da população brasileira, como apontado na figura 3. 
Figura 3 - Mundo se preocupa sobre a utilização das notícias falsas como arma

\section{World Worried About Fake News as a Weapon}

Percent who worry about false information or fake news being used as a weapon

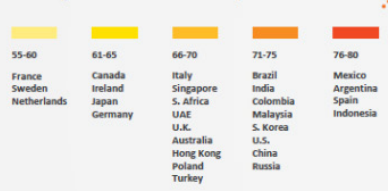

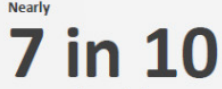

worry about false

information or fake news

being used as a weapon

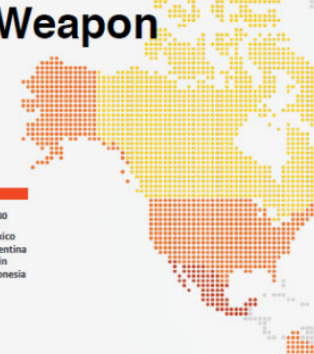

Canadian Conservative leader's campaign
manager roots ou enemies using fake ne Pope criticizes
spread of fake news spread of fake news

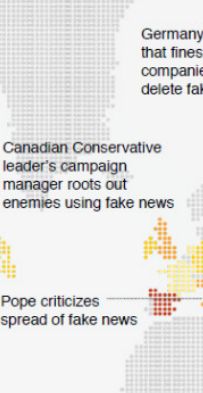

Source: 2018 Edelman Trust Barometer. ATT_MED_AGR. Below is a ilst of statements. For each one, please rate how much you agree or disagree with that statement Fake news disrupts

Fonte: Edelman Trust Barometer, 2018.

\section{O Edelman Trust Barometer de 2018 também} mostra que as pessoas compreendem a mídia como o conjunto de plataformas (mídias sociais e mecanismos de busca, por exemplo) e os indivíduos que agem nestas diferentes plataformas. Assim, em uma pergunta mais específica descobriu-se que a confiança no jornalismo (mídia tradicional ou online), especificamente, cresceu cinco pontos percentuais no último ano, alcançando o patamar de $59 \%$ entre a população mundial. A credibilidade jornalística, portanto, estaria se recuperando em um momento comunicacional que a fonte de informação pode definir se uma pessoa acredita na notícia ou a descarta como "fake news".

A mesma recuperação, no entanto, não pode ser dita sobre organizações noticiosas. Além de $50 \%$ afirmar que não consome materiais noticiosos com frequência, muitos se mostraram céticos em relação a atuação e interesses dos meios de comunicação noticiosos. Dessa forma, a percepção de $66 \%$ da população é de que a maior preocupação é atrair audiências e não reportar os fatos; $65 \%$ acredita que uma organização colocaria em risco a precisão das informações para dar um "furo" e 59\% acredita que é mais importante para essas organizações defender uma ideologia do que informar o público.

\subsection{O contexto brasileiro}

O ecossistema comunicacional brasileiro, apesar de também apresentar dificuldades há algum tempo, com maior ênfase nas manifestações de junho de 2013 até o impeachment da ex-presidenta Dilma Rousseff (Carvalho \& Belda, 2017), reagiu de forma diferenciada tendo em vista o seu contexto social, econômico e cultural. A sensação de que a mídia tradicional não conseguia representar os diversos 
interesses da sociedade deu espaço, ainda em 2013, para o florescimento de mídias alternativas no país. Essas mídias, por questões de composição orgânica, financiamento para o funcionamento e manutenção entre outras, muitas vezes atuam através das mídias sociais. O primeiro contato e a forma de relacionamento entre os comunicadores e o seu público é muito mais baseada na interação das redes sociais, como Facebook, Instagram e Twitter, do que as mídias tradicionais que migraram para esses dispositivos posteriormente a sua atuação na sociedade.
Assim, a relação entre jornalismo (mídia tradicional e mídia online) e plataforma (mídias sociais e mecanismos de buscas) apresenta-se de uma forma diferente para o público brasileiro nos últimos anos. Dentre os 28 países que fazem parte da pesquisa do Trust Barometer, o Brasil é um dos quatro países que confiam mais em plataformas do que no jornalismo (figura 4). A diferença de apenas 1\% (64 e $63 \%$, respectivamente) é mínima, mas ainda assim representa um interessante resultado tendo em mente que a maior parte dos países apresentou uma tendência a acreditar muito mais no jornalismo.

Figura 4 - Jornalismo é mais confiável do que plataformas em 21 países

JOURNALISM I PLATFORMS

\section{Journalism More Trusted Than Platforms in 21 Countries}

- Average trust in traditional and online-only media

Average trust in search engine and social media plattorms

Gap in trust in journalism vs. platforms

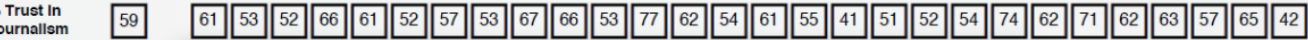

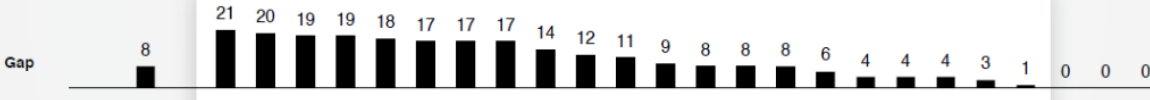

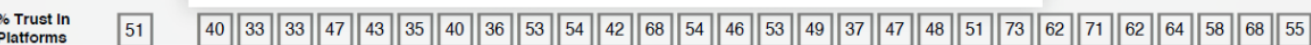
\|\|\|\|$^{m}\|\|\|\|\|\|\|\|$

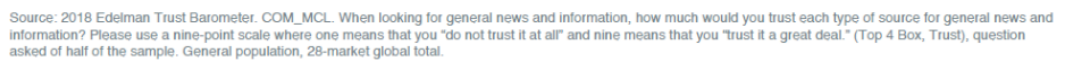

Fonte: Edelman Trust Barometer, 2018.

\section{A PERCEPÇÃO DO PÚBLICO}

Com a necessidade de entender qual é a relação do público brasileiro com a mídia e com as informações que consomem, produzimos um questionário com cinco questões e o distribuímos no segundo semestre de 2017. Um total de 143 pessoas responderam. A pesquisa também buscou mapear a percepção da credibilidade e da confiança no jornalismo atualmente por parte do público. A distribuição se deu de duas 
diferentes formas: 67 pessoas responderam online e 76 pessoalmente, por meio de questionário impresso. A primeira questão (Como você define a sua posição como leitor de notícias?) tinha como objetivo entender quem é público brasileiro que consome conteúdos noticiosos. Em sua maioria, cerca de $38 \%$, os indivíduos se identificaram como uma pessoa que tem contato regular com jornais, ainda que não os assinem. A presença de pessoas que se informam predominantemente pela internet também é significativa, aproximadamente $42,6 \%$. Enquanto que uma minoria é assinante de publicações jornalísticas, $15,4 \%$. E apenas $12,6 \%$ das pessoas afirmaram não consumir notícias durante o seu dia a dia.

Os resultados da segunda questão (Você acha que as notícias às quais você tem acesso são confiáveis?) apontam que a ideia de que a mídia é confiável continua presente para a maior parte dos entrevistados: $60 \%$ das pessoas entrevistadas afirmaram que confiam sempre ou geralmente nas informações as quais têm acesso. Enquanto que $38,5 \%$ afirmaram que confiam poucas vezes ou nunca. $E$ apenas uma pessoa $(0,7 \%)$ afirmou não ter uma posição formada a respeito.

O cruzamento de dados mostra que apenas uma pessoa que é assinante de publicações jornalísticas não confia nas informações nas quais tem acesso. Entre aqueles que não tem confiança nas notícias, $40 \%$ dos respondentes afirma ser um indivíduo que se informa a partir de diferentes fontes na internet.
Um grande número dessas pessoas, 36\%, também afirmaram que apesar de não assinarem nenhuma publicação, leem jornais com frequência.

Para avaliar a confiabilidade dos meios de comunicação de forma mais específica, o formulário contava com uma questão em que cada indivíduo apontava a sua confiança em diferentes mídias. Dessa forma, o jornal impresso foi considerado o meio mais confiável, sendo apontado por $71 \%$ das respostas como muito confiável ou confiável. No entanto, como mostram os dados da primeira questão apenas 15,6\% assinam uma publicação jornalísticas e $38 \%$ dos entrevistados afirmaram ter contato com algum jornal.

Os números mais baixos em confiabilidade foram atribuídos a três formas de divulgação de conteúdo online: redes sociais, blogs e canais de vídeo. Esses meios, portanto, tiveram um alto grau de rejeição por parte dos entrevistados, $89,5 \%, 80,4 \%$ e $74 \%$, respectivamente, os consideraram pouco ou nada confiáveis. Importante observar, porém, que 42,6\% das pessoas que responderam à pesquisa se informam predominantemente pela internet.

Outro dado que chama a atenção nesse levantamento é o fato de que a confiabilidade da televisão está tecnicamente empatada com confiança atribuída aos sites de notícias. Enquanto a televisão tem a confiança de $44 \%$ do público, os sites jornalísticos têm a confiança de mais de $45 \%$ das pessoas. 
Figura 5 - Avaliação individual da confiabilidade nos meios de comunicação

\section{Avaliação individual dos meios de comunicação}

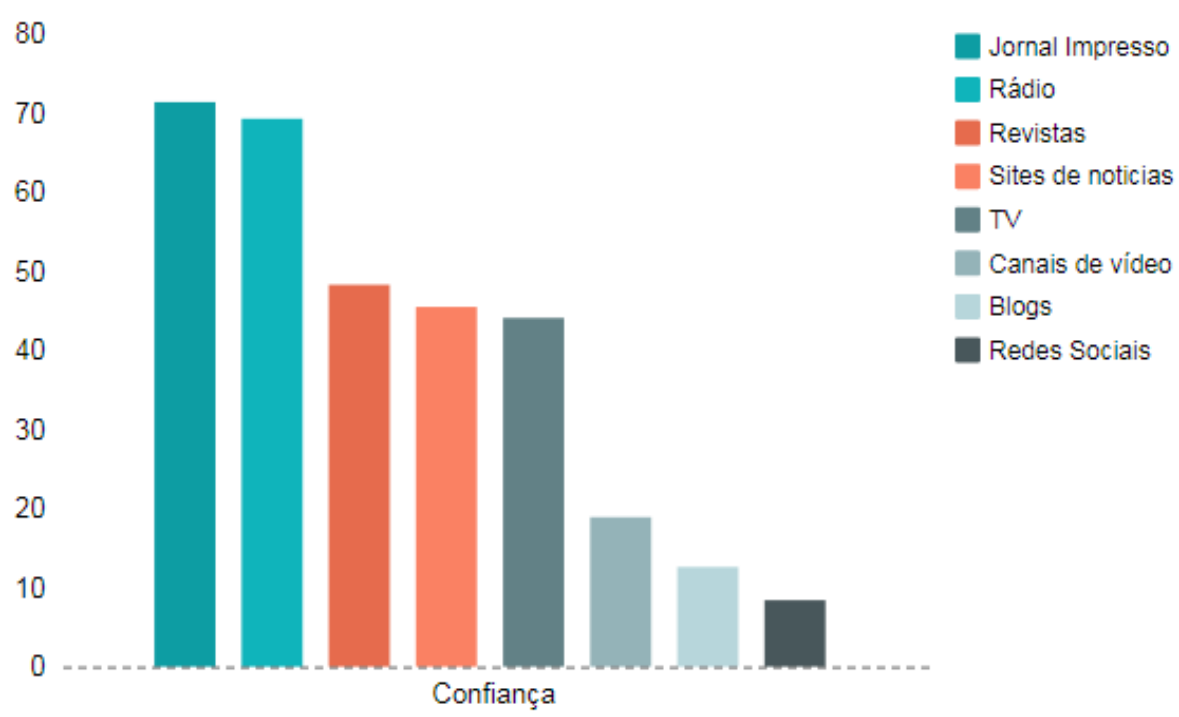

$\mathrm{Na}$ questão que buscava mapear quais eram as independência editorial e a correção ágil dos erros características que o público considerava ser (Projeto Credibilidade, 2017).

importantes para a atribuição de credibilidade em Dentre estas, três qualidades foram as mais uma matéria jornalística foram disponibilizadas oito opções. Sendo elas baseadas em uma pesquisa prévia realizada pelo Projeto Credibilidade entre jornalistas brasileiros. O ponto em utilizar esses mesmos critérios é a comparação entre aquilo que os jornalistas consideram qualidade do credível versus a percepção do público. Para os profissionais de assinaladas pelo público: "Investigação e apuração rigorosa das informações (com referência a documentos, testemunhos e dados objetivos)" com $79,6 \%$, "Indicação de que as fontes foram checadas e verificadas após a apuração da reportagem", com $44 \%$ e "Autoria identificada (nome do autor / produtor é expresso na matéria)", com 40,5\%. Essas comunicação, os três atributos de valor para uma matéria jornalística ser considerada de qualidade escolhas refletem na atribuição dos valores de precisão e apuração, checagem e verificação e na e credível são: a precisão, apuração e correção, a identificação do jornalista responsável pelo conteúdo, respectivamente. 
Figura 6 - Indicadores de credibilidade segundo os respondentes da pesquisa

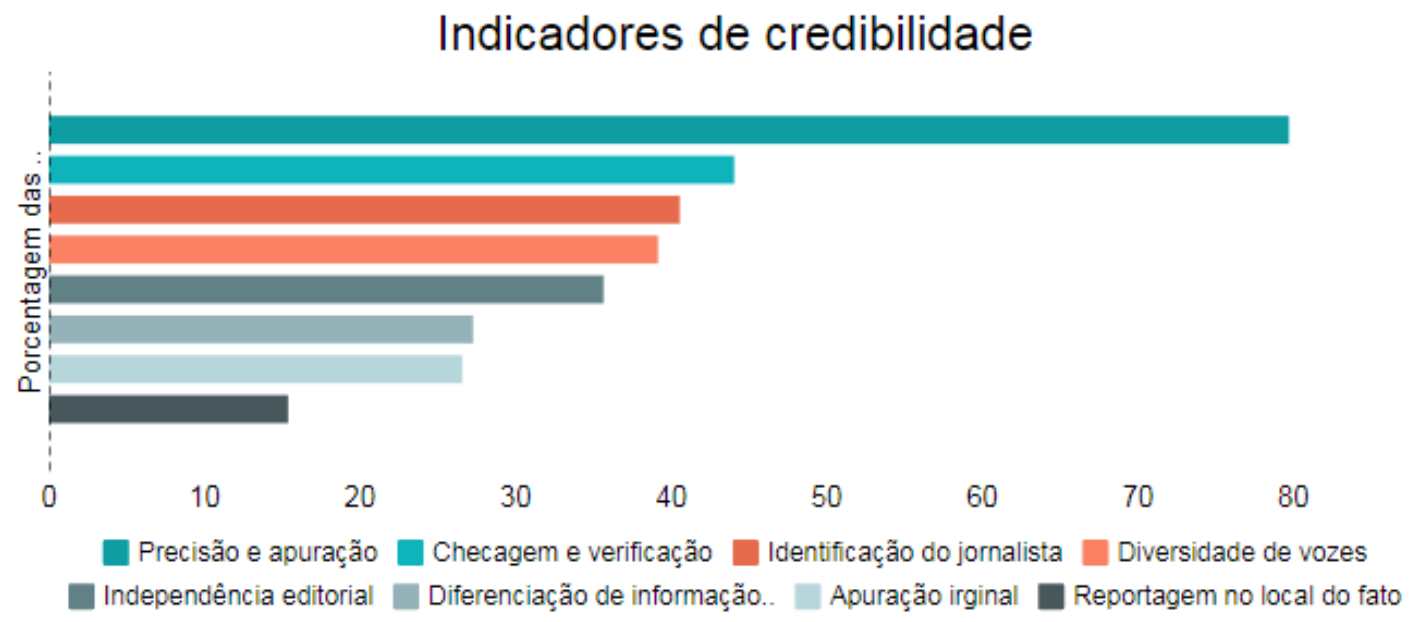

Também havia uma questão referente aos critérios de atribuição da confiança por parte dos consumidores de notícias a organizações jornalísticas. Nesse quesito, "Comprometimento com um código de ética", "Transparência do jornalista em relação aos seus conhecimentos e possíveis conflitos de interesses" e "Independência editorial (sem interferência de forças econômicas e/ou políticas)" dominaram a maior parte das escolhas, aparecendo em aproximadamente $60 \%$.

A mensuração das respostas demonstra que apesar do público brasileiro afirmar que continua confiando na instituição mídia e nos produtos noticiosos que consomem, há um desequilíbrio nessa atribuição. A maior parte dos entrevistados não demonstram tanta confiança na avaliação individual dos meios de comunicação a quais tem acesso no dia a dia.

\section{CONSIDERAÇÕES FINAIS}

A pesquisa quantitativa que realizamos em 2017 demonstra que em muitos pontos o público e os profissionais de comunicação buscam um mesmo padrão de qualidade no jornalismo. A presença constante de critérios como precisão e apuração, checagem e verificação e independência editorial aponta para uma visão similar dos atributos necessários para a atribuição de credibilidade e de confiança a conteúdos jornalísticos.

No entanto, os números de atribuição de confiabilidade nos meios de comunicação indicam que esse mesmo público não confia nas informações que recebe diariamente. Assim, se levarmos em conta que os critérios dos dois grupos comunicacionais são os mesmos, algum elemento dos conteúdos jornalísticos não atendem ao padrão auto-imposto e esperado ou ainda essas características, ainda que presentes, não 
estão sendo percebidas pelo público para que possa ocorrer a atribuição de credibilidade.

Como dito, a percepção de que algo é credível passa por diferentes processos objetivos e subjetivos. E como não é possível ter um controle nos critérios subjetivos, como aderência ideológica entre o meio e o indivíduos, é necessário que haja alinhamento dos objetivos. A ideia, como já apontado, não é inovadora, seja no jornalismo ou em qualquer outra forma de comunicação: é preciso haver correspondência entre produtores e receptores.

Assim, ainda que o contrato comunicacional não esteja sendo quebrado, o público ainda tem a impressão de que não pode mais confiar no jornalismo. A percepção de que algum elemento do contrato inter-relacional da comunicação - quem diz o quê, para quem, com que intenções, em que condições e de que forma (Charaudeau, 2010) - não está sendo explicitado ou então não condiz com a verdade faz com que a percepção de credibilidade seja impossível.

A premissa que permite ao jornalismo atuar na sociedade como uma forma de retratar a realidade é a confiança da população de que seu conteúdo é verídico e verdadeiro, ou seja, credível. Quando essa ideia é colocada em dúvida, a própria atividade passa a ser questionada em sua legitimidade dentro de uma democracia e em sua correspondência com os fatos e a realidade.

Se faz necessário, portanto, que o jornalismo se reconecte com o seu leitor ou ao menos estabeleça por qual motivo a percepção do público é de que a atividade não é confiável. Assim, será possível realizar as mudanças necessárias para que além de jornalistas e público terem como base os mesmo critérios para a atribuição de credibilidade, esses critérios encontrem eco na prática jornalística e na percepção da mesma.

\section{NOTAS}

1. Iniciativa do Instituto para o Desenvolvimento do Jornalismo (Projor) e o Programa de Pós-Graduação em Mídia e Tecnologia (PPGMiT), da Universidade Estadual Paulista (Unesp), que replica no Brasil o estudo já realizado nos Estados Unidos (Trust Project, realizado pela parceria entre Trustworthy Journalism Initiative, Google e Fundação Markkula). Os objetivos são refletir sobre a fragmentação da notícia e desenvolver ferramentas e técnicas para identificar e promover um jornalismo digital confiável e de qualidade. e link para o projeto. Mais informações: https://www.credibilidade.org

2. Tradução livre: "[...] confiança, credibilidade e qualidade (e os sub-fatores dos quais eles são compreendidos) são intrinsecamente subjetivos, ou seja, eles podem ser interpretados de diferentes formas e indiscutivelmente pode ter diferentes níveis de importância dependendo do usuário da informação ou do contexto".

3. Tradução livre: "Nesta era caracterizada por um excedente de informações de variadas fontes acessíveis para qualquer pessoa online, credibilidade tem se tornado mais importante. Usuários escolhendo através de um infinidade de informações disponíveis precisam discernir em que acreditar e o que dispensar como simples 
conversar online. Isso é verdade especialmente para os mais jovens, que dependem da Internet mais do que as gerações mais velhas".

4. Pós-verdade: um adjetivo definido como «relacionado a ou que denota circunstâncias nas quais fatos objetivos são menos influentes na formação da opinião pública do que apelos à emoção e à crença pessoal». Definição pelo Dicionário de Oxford (https://en.oxforddictionaries.com/word-of-the-year/word-of-the-year-2016)

5. Câmera de eco: grupos que pensam da mesma forma e polarizam as opiniões e reafirmam o mesmo conjunto de ideias, crenças e opiniões. Esses grupos são formados a partir do consumo de notícias por meio das redes sociais, ou seja, um meio que não é mediado.

6. Tradução livre: "Se um item noticioso, seja fundamentado ou não, é aceito como verdadeiro por um usuário pode ser fortemente afetado por normas sociais ou por quanto esse item é coerente com o sistema de crenças do usuário $(58 ; 70)$. Apesar das entusiásticas afirmações de que mídias sociais estão gerando uma vasta «inteligência coletiva» disponível para todos (71), muitos mecanismos fazem com que falsas informações ganhem aceitação, o que em retorno gera falsas crenças que, uma vez adotadas por um indivíduo, são altamente resistentes à correção $(72 ; 73 ; 74 ; 75)$. Usando extensivas análises qualitativas mostramos que hegemonia social é o impulsionador primário da difusão de conteúdo, e um resultado frequente é a formação de aglomerados homogêneos e polarizados (frequentemente chamados de «câmaras de eco»)".

\section{REFERÊNCIAS}

BENETTI, M. \& LISBOA, S. O jornalismo como crença verdadeira justificada_Brazilian Journalism Research. v. 11, n. 2 , 2015.

CARVALHO, P. H. V. de \& BELDA, F. R. Multiparcialidade, dialogia e cultura participativa como reação à pós-verdade: uma abordagem discursiva sobre o jornalismo. Culturas Midiáticas, Ano X, n. 18 - jan-jun/2017 - ISSN 1983-5930 - http://periodicos.ufpb.br/ojs2/index.php/cm. Acesso em agos. de 2017.

CHARAUDEAU, P. Discurso das mídias. São Paulo: Contexto, 2010. 285 p

DEL VICARIO, M. The role of confirmation bias in the emergence of echo chambers: a data-driven approach. (PhD Thesis) IMT School for Advanced Studies Lucca, 2016 pp. 127. http://e-theses.imtlucca.it/199/ Acessado em 15 de mar. de 2017

Edelman Trust Barometer. Edelman Intelligence, United Entertainment Group. 2016. http://www.edelman.com/globalresults/. Acessado em 03 de fev. de 2018.

Edelman Trust Barometer. Edelman Intelligence, United Entertainment Group. 2017. http://www.edelman.com/globalresults/. Acessado em 20 de jan. de 2017. 
Edelman Trust Barometer. Edelman Intelligence, United Entertainment Group. 2018. http://www.edelman.com/globalresults/. Acessado em 03 de fev. de 2018.

LEWICKI, R. J. \& TOMLINSON, E. C. Trust and Trust Building. Beyond Intractability. Eds. Guy Burgess and Heidi Burgess. Conflict Information Consortium, University of Colorado, Boulder. Posted: December 2003. http://www. beyondintractability.org/essay/trust-building. Acessado em 26 de jan. de 2017.

LISBOA, S. S. de M. Jornalismo e a credibilidade percebida pelo leitor: independência, imparcialidade, honestidade, objetividade e coerência. Dissertação de mestrado para o Programa de Pós-Graduação em Comunicação e Informação da Universidade Federal do Rio Grande do Sul, 2012.

NURSE, J., AGRAFIOTIS, I., GOLDSMITH, M., CREESE, S. \& LAMBERTS, K. Two sides of the coin: measuring and communicating the trustworthiness of online information, 2014. Journal of Trust Management 2014, 1:5 http:// www.journaloftrustmanagement.com/content/1/1/5

Projeto Credibilidade. Pesquisa com jornalistas profissionais (2016-2017), 2017. Disponível em: https://www.credibilidade. org/pesquisa. Acesso em maio de 2018

SERRA, P. A credibilidade da informação na web. 2006a. BOCC. Disponível em: http://www.bocc.ubi.pt/pag/serra-paulocredibilidade-web.pdf. Acessado em 31 de jan. de 2017.

SERRA, P. O princípio da credibilidade na seleção da informação mediática. 2006b. BOCC. Disponível em: http://www. bocc.ubi.pt/pag/serra-paulo-credibilidade-seleccao-informacao.pdf. Acessado em 31 de jan. de 2017.

SWASY, A., TANDOC E., BHANDARI, M. \& DAVIS, R. Traditional Reporting More Credible than Citizen News. Newspaper Research Journal, 2015, Vol. 36(2) 225-236

TAMBOSI, O. Jornalismo e teorias da verdade. Intercom - Revista Brasileira de Ciências da Comunicação. São Paulo, v.30, n.1, p.35-48, 2007. 